\title{
Spatial Distribution of Cordex Regional Climate Models Biases over West Africa
}

\author{
Alioune Badara Sarr, Moctar Camara*, Ibrahima Diba \\ Laboratoire d'Océanographie, des Sciences de l'Environnement et du Climat (LOSEC), Université Assane SECK \\ de Ziguinchor, Ziguinchor, Senegal \\ Email:
}

Received 12 July 2015; accepted 21 September 2015; published 24 September 2015

Copyright @ 2015 by authors and Scientific Research Publishing Inc.

This work is licensed under the Creative Commons Attribution International License (CC BY). http://creativecommons.org/licenses/by/4.0/

(c) (i) Open Access

\section{Abstract}

The objective of this work is to analyze the spatial distribution of biases of nine (9) regional climate models (RCMs) and their ensemble average used under the framework of Coordinated Regional climate Downscaling EXperiment (CORDEX) project over West Africa during the summer period. We assessed the ability of RCMs to represent adequately West African summer rainfall by analyzing some statistical parameters such as the relative bias, the standard deviation, the root mean square error (RMSE) and the correlation coefficient between observation data (GPCP used as reference) and regional climate models outputs. We first analyzed the relative bias between GPCP climatology and the other available observed data (CRU, CMAP, UDEL, GPCC, TRMM and their ensemble mean). This analysis highlights the big uncertainty on the quality of these observed rainfall data over West Africa which may be largely due to the rarity of in situ measurement data over this region. The statistical analysis with respect to GPCP rainfall shows the presence of large relative bias values over most part of West Africa for engaged RCMs. However their ensemble mean outperforms individual RCMs by exhibiting the weakest relative change. The RMSE values are weak over West Africa except over and off the Guinea highlands for RCMs and the Era-interim reanalysis. The spatial distribution of the coefficient of correlation between the observation data and RCMs shows that all models (except HIRHAM) present positive values over the Northern Sahel and the Gulf of Guinea. The model of the DMI exhibits the weakest values of correlation coefficient. This study shows that RCMs simulate West African climate in a satisfactory way despite the fact that they exhibit systematic biases.

\section{Keywords}

CORDEX, Regional Climate Models, Rainfall

\footnotetext{
${ }^{*}$ Corresponding author.
} 


\section{Introduction}

Atmosphere-Ocean General Circulation Models (AOGCMs) have been extensively used to produce climate change scenarios under various greenhouse gas emission hypotheses over West Africa [1]-[3]. But these projections are limited by the large spread between global climate models due to the fact that they are not unable to resolve fine scale features (vegetation variations, complex topography, coastlines) which are important parameters for the physical response of the climate [4] [5] because of their coarse resolution. Due to their high computational demands over long time periods of simulation, these models (AOGCMs) are not the ideal tool to provide high spatial resolution climate change projections needed for impact studies. They are generally supplemented by regional climate models (RCMs) using dynamical downscaling techniques in the aim to provide reliable climate change scenarios [6] [7]. Moreover, because of their high spatial resolution which takes into account land surface heterogeneity, numerous studies show that these models produce reliable monsoon circulation over West Africa; a region known for its unreliable rainfall regime which is highly variable on intraseasonal, interannual and interdecadal time scales [8]-[10]. Contrary to AOGCMs which have been widely used for climate change ensemble experiments, few RCMs ensemble simulation projects have already taken place: PRUDENCE and ENSEMBLE [11]. But these coordinated experiments focused on limited areas. The COordinated Regional climate Downscaling EXperiment (CORDEX) project is the latest ensemble experiments involving many research centers throughout the word which aims to produce high resolution climate change scenarios at regional level for climate change impact studies and to characterize associated uncertainties [12]-[15] using the latest generation of regional climate models throughout most part of the world.

Two types of simulations have been performed under the framework of this project: the present day run (1989-2008) which is designed to assess the performance of engaged RCMs forced by perfect boundaries (Erainterim reanalysis) and the climate change projections whose goal is to help understand the evolution of the climate during the near and far future (2006-2100) and to assess climate change impacts.

This study analyses the present-day simulation of the precipitation over the West Africa during the summer period in the aim to better understand the spatial distribution of RCMs errors over the whole West African region during the summer time instead of focusing only on box average analysis over some sub-regions. Data and methods are presented in the next section followed by the results and the discussion.

\section{Data and Methods}

High resolution rainfall data of nine (9) CORDEX regional climate models are analyzed in this study: ICTPRegCM3, DMI-HIRHAM, CNRM-ARPEGE, UC-WRF, UQAM-CRCM5, MPI-REMO, SMHI-RCA, UCTPRECIS, KNMI-RACMO. The spatial resolution is $0.44^{\circ}$ and the considered period in this study is 1998-2008. Additional information about the analysed models are available at Table 1. CORDEX regional climate models outputs can be downloaded using the Earth System Grid Federation (ESGF) nodes such as: http://esgf-node.ipsl.fr/.

Models simulations as well as their ensemble runs are compared with the Era-interim reanalyses data used to initialize and drive the regional climate models [26] and observed precipitation data such as the Global Pre-cipitation Climatology Project-GPCP [27], Tropical Rainfall Mission Measurement (TRMM, 3B42; [28]), the

Table 1. List of considered CORDEX regional climate models.

\begin{tabular}{|c|c|c|}
\hline Name & Institution & References \\
\hline CNRM-ARPEGE & CNRM, France & Déqué [17] \\
\hline DMI-HIRHAM & DMI, Denmark & Christensen et al. [18] \\
\hline ICTP-RegCM3 & ICTP, Italy & Pal et al. [19] \\
\hline MPI-REMO & MPI, Germany & Jacob et al. [20] \\
\hline KNMI-RACMO & KNMI, Netherlands & Meijgaard et al. [21] \\
\hline UCT-PRECIS & University of Cape Town, South Africa & Jones et al. [22] \\
\hline SMHI-RCA35 & SMHI, Sweden & Samuelsson et al. [23 \\
\hline UC-WRF & Universidad de Cantabria, Spain & Skamarock et al. [24] \\
\hline UQAM-CRCM5 & Université du Québec à Montréal (UQAM), Canada & Zadra et al. [25] \\
\hline
\end{tabular}


Global Precipitation Climatology Center (GPCC; [29]), the observation of the Climate Research Unit (CRU; [30]) and the rainfall product of the University of Delaware (UDEL; [31]) from 1998 to 2008. CRU and UDEL data are essentially a compilation of rain gauges measurements; while TRMM, GPCP and GPCC rainfall data are a combination of in situ measurements (rain gauges) and satellite estimations. These observed data are at the same spatial resolution than the regional climate models runs $\left(0.44^{\circ}\right)$. The simulation domain as well as the considered sub-domains (Western Sahel, Central Sahel, Eastern Sahel and the Guinean region) and the topography are represented in Figure 1.

We evaluate systematic biases of CORDEX regional climate models by analyzing some statistical parameters such as the root mean square errors (RMSE), the relative bias, the standard deviation and the coefficient of correlation over the whole West African domain and the four selected (4) sub-domains:

The relative bias (RB) and the RMSE are calculated as follows:

$$
\begin{gathered}
\mathrm{RB}=100 * \frac{1}{n} \sum_{i=1}^{n} \frac{\left(M_{i}-O_{i}\right)}{O_{i}} \\
\mathrm{RMSE}=\sqrt{\frac{\sum_{i=1}^{i=n}\left(M_{i}-O_{i}\right)^{2}}{n}}
\end{gathered}
$$

where $n$ is the number of time steps; $O_{i}$ and $M_{i}$ are respectively the time series of the observed (GPCP climatology) and the simulated rainfall.

The correlation coefficient $(r)$ is calculated using this formula:

$$
r=\frac{\operatorname{cov}(O, M)}{\sigma_{O} \sigma_{M}}
$$

where cov and $\sigma_{x}$ represent the covariance and the standard deviation of $x$. $O$ and $M$ represent respectively the observed and the simulated rainfall time series.

The coefficient of variation is calculated as follows:

$$
C_{v}=100 * \frac{\sigma}{\mu}
$$

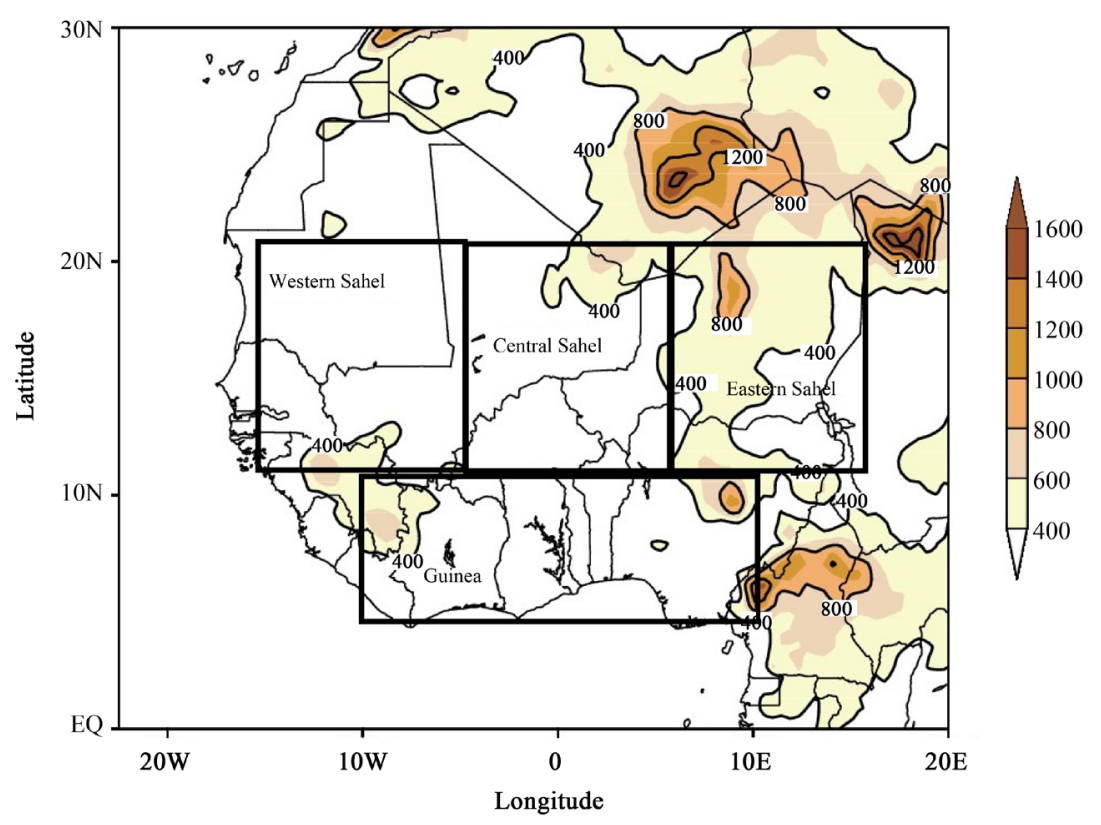

Figure 1. Topography of the simulation domain (West Africa) and considered subdomains (Western Sahel, Central Sahel, Eastern Sahel and Guinea). 
where $\sigma$ and $\mu$ are respectively the standard deviation and the mean of the observed or the simulated rainfall for the considered period (1998-2008).

\section{Results and Discussions}

The first step of this work is to analyze the available observed data used over West Africa for model validation purposes. These data are generally a combination of in situ measurements from rain gauges and satellite rainfall. Figure 2 represents the summer rainfall mean (June-September from 1998 to 2008) for the GPCP climatology

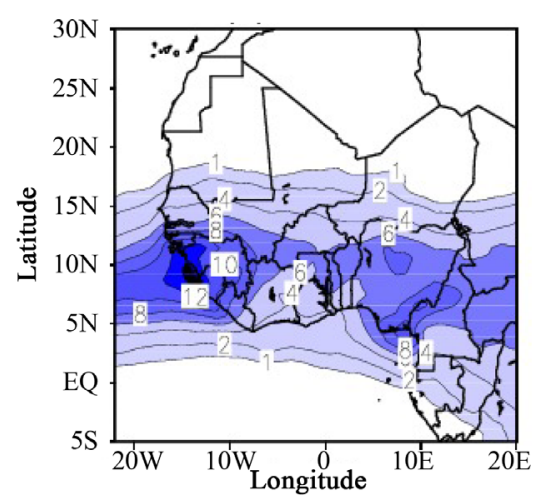

(a) GPCP

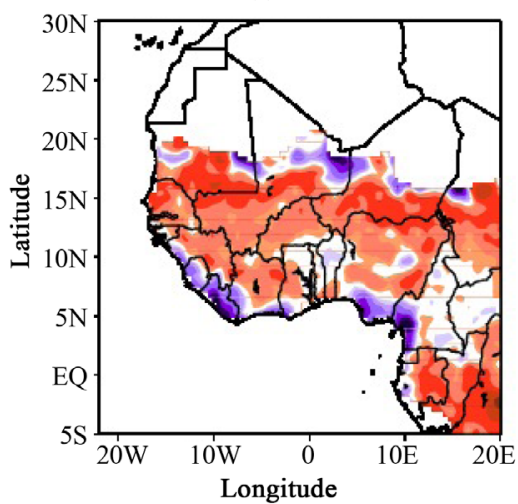

(b) GPCC (GPCP)

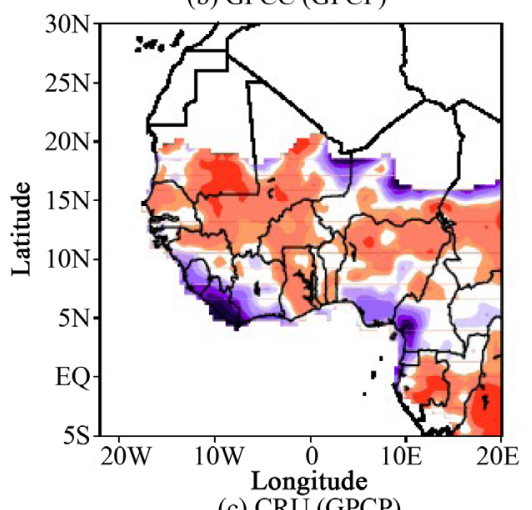

(c) CRU (GPCP)

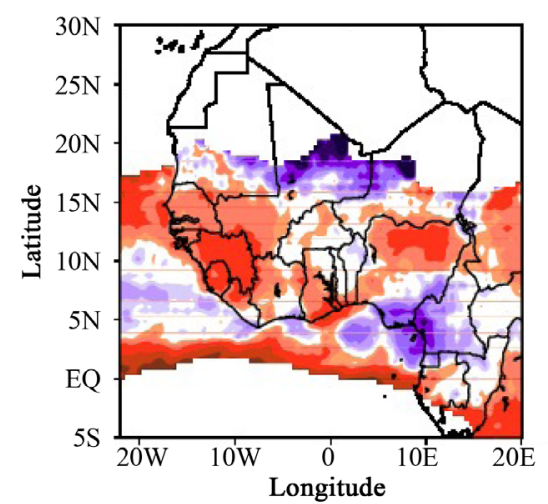

(d) TRMM (GPCP)

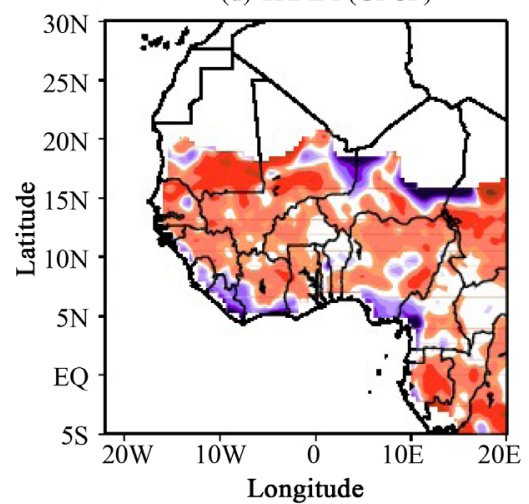

(e) UDEL (GPCP)

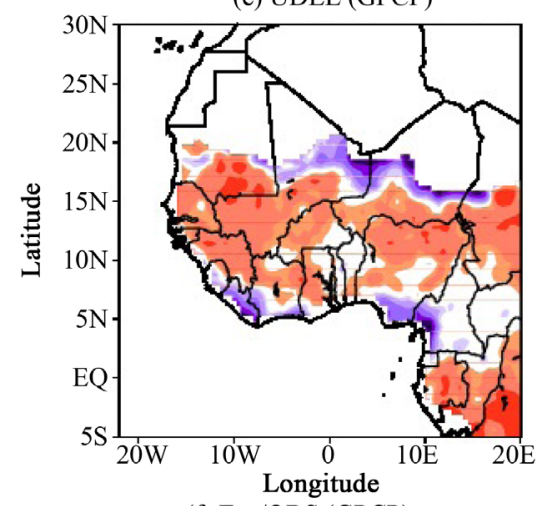

(f) Ens/OBS (GPCP)

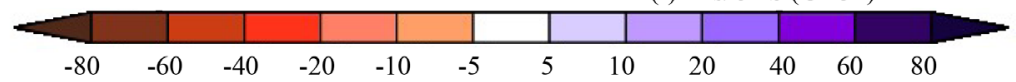

Figure 2. Mean summer rainfall (June-September) averaged from 1998 to 2008 for GPCP data (a) and the relative anomaly with respect to GPCP data for different observed rainfall products (GPCC, TRMM, UDEL and CRU) and their ensemble mean from 1998 to 2008. The units for GPCP and the relative change are respectively $\mathrm{mm} /$ day and \%. 
and the relative bias with respect to the GPCP climatology of the remaining observed rainfall products. GPCP climatology shows a North-south gradient with exceptions around mountainous regions where the rainfall maximum is generally located. The relative bias highlights the big uncertainty on the quality of the observed rainfall over West Africa and this may be due to the rarity of in situ measurement stations over most parts of the region. Dry biases which sometimes reach $40 \%$ in the soudano-Sahelian band have been diagnosed. Wet biases are noted over the Guinean coast and over the Northern Sahel. The dry and wet biases intensities are more important in the case of TRMM data. Larger dry (wet) biases are located over the Guinea gulf region, Cameroon mountains and the Northern part of Sahel (respectively over the Guinea Gulf and Jos highlands). The ensemble mean of observations (arithmetic mean of the observation data) shows a distribution similar to most observed products with however reduced biases suggesting that it may be used as a reference for the evaluation of climate models performance. Nevertheless, many studies show that the GPCP climatology represents better the West African rainfall spatio-temporal variability and that is the reason why we chose it as the reference for the observation data [13] [32].

The next step is to evaluate regional climate models errors with respect to GPCP climatology by analyzing relevant statistical parameters. The root mean square error (RMSE) allows to measure the amplitude of errors committed by models; whereas the bias gives an indication of the sign of errors (overestimation or underestimation).

Figure 3 shows the relative bias with respect to GPCP observations over West Africa for the driving field EraInterim, the RCMs and their ensemble mean. The RegCM3.5 shows dry biases over North-Western Sahel and the Gulf of Guinea. PRECIS model shows a complex spatial structure: wet biases over most part of Sahel and dry biases over the coastal areas followed by wet relative change over the ocean. The forcing data (Era-Interim) presents an opposite structure when compared with the Precis model. This result highlights the fact that the solution simulated by regional climate models does not depend only on the forcing and initialization data but the internal variability of the latters may also play greater role.

CRCM5, WRF and the SMHI models show dry (wet) biases over the Sahel (Gulf Guinea region) with larger relative changes recorded in the case of WRF. The ARPEGE model shows essentially dry biases over the study regions with wet biases over small regions located over the Gulf of Guinea, while the model of DMI exhibits very high biases exceeding $80 \%$ over the ocean. The average of all models (ENSEMBLE) shows the weakest biases. But it is necessary to state again the fact that observation data present uncertainties over West Africa due to the deficit of in situ measurement especially over mountainous, forest and desert areas.

When we considered the average over the considered sub-domains of the relative bias with respect to GPCP of climate models and the forcing data (Table 2), CORDEX RCMs and Era-Interim reanalyses over the Western Sahel, the model of the CNRM and the driving field Era-Interim present dry biases of the order of $40 \%$ whereas the weakest bias is observed for the RegCM3 model. Over the central Sahel, in addition with the CNRM model and the Era-interim data, the Canadian model (UQAM-CRCM5) present a strong dry bias. The remaining RCMs show weak biases. Over the Eastern Sahel, ERA-Interim reanalyses presents the strongest bias followed by the Canadian model (UQAM). The Guinean zone is characterized by low biases for the majority of models even if the RACMO and WRF present respectively dry and wet biases of the order of 30\%. At the end of this analysis, it is necessary to highlight the difficulties of ARPEGE model and the forcing data (Era-Interim reanalysis) to correctly simulate the West African summer rainfall especially over the Sahel due to the fact that they exhibit strong biases over the Northern part of that region (Figure 3).

In the aim to go deeper in the characterization of the differences between the observation data and the RCMs CORDEX data, we computed the root mean square errors which quantify the magnitude of errors done by RCMs (Figure 4). Overall, the RMSE is weak over West Africa except over and off the Guinea highlands. This region is characterized by the lack of in situ measurement suggesting that the RCMs may even be better than observation because they are able to resolve local features (orography) that are important for the physical response of the climate [11]. The DMI model shows the greatest RMSE especially over the ocean; this model shows also RMSE values greater than $7 \mathrm{~mm} /$ day over a region extending from Burkina-Faso to Nigeria. The RACMO, RCA and PRECIS models present the weakest values of RMSE. The ensemble mean like most of RCMs exhibits strong values off Fouta Djallon highlands.

Table 3 represents the average values of the RMSE between the climate models and the observation data (GPCP) over the considered sub-domains. Over the western Sahel, CNRM, DMI, MPI and SMHI models present values superior to $3 \mathrm{~mm} / \mathrm{d}$. Over the Central and the Eastern Sahel, RMSE values are weaker; only the DMI model 

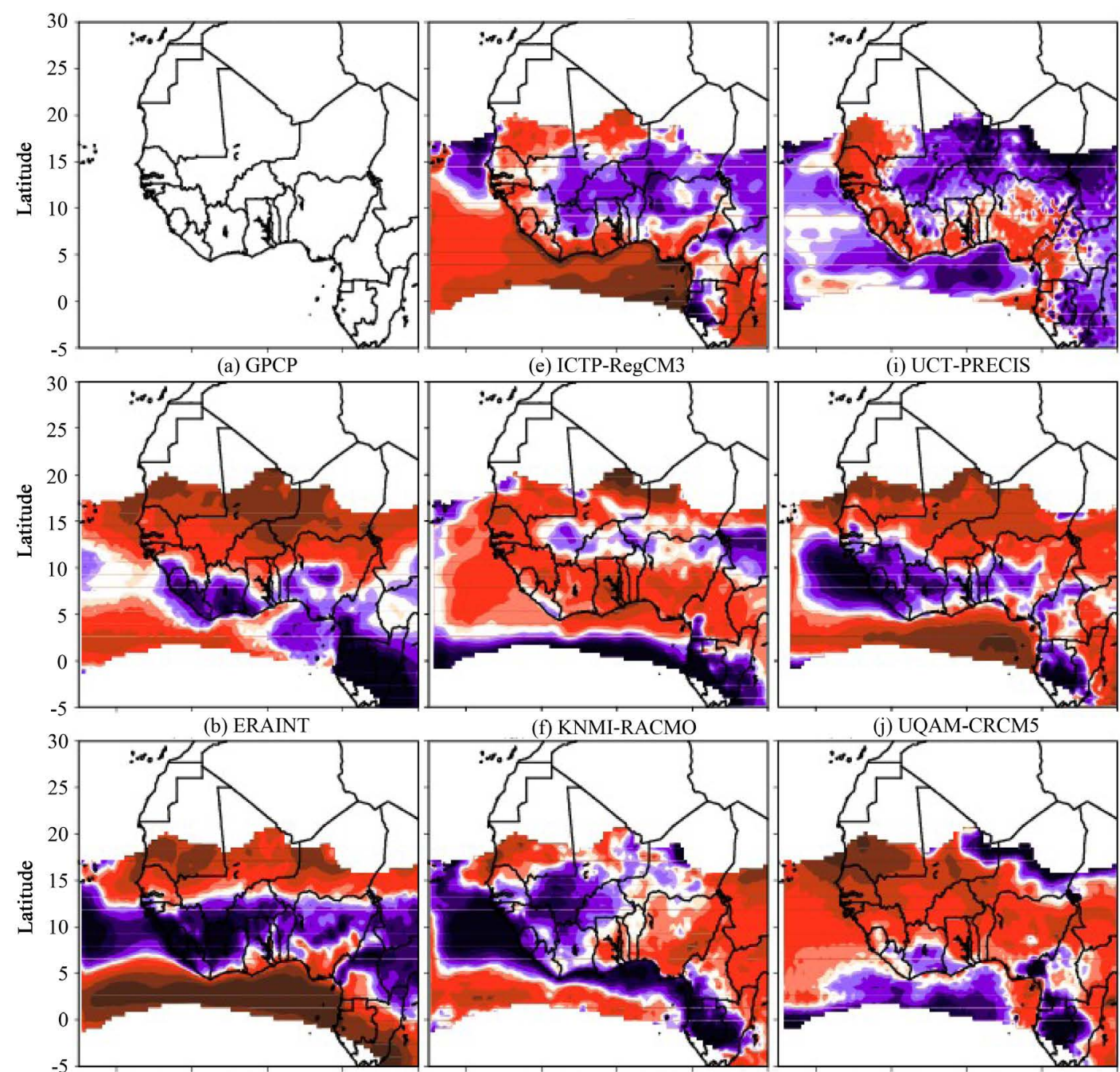

(j) UQAM-CRCM5

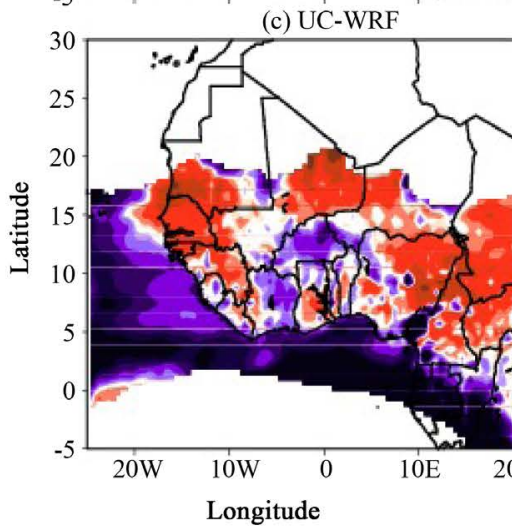

(d) DMI-HIPHAM

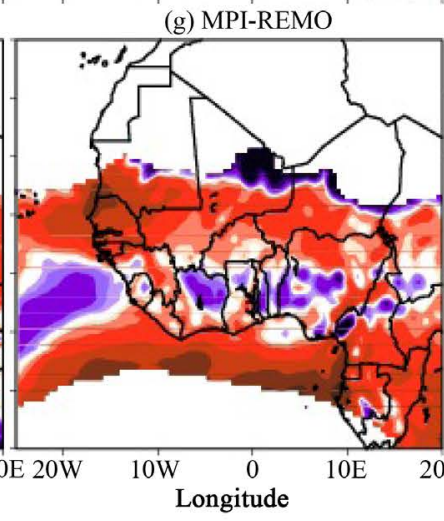

(h) SMHI-RCA35

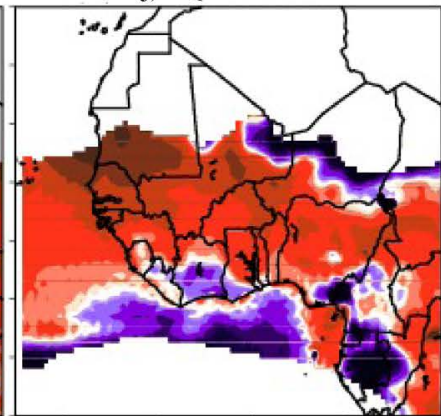

(k) CNRM-ARPEGE

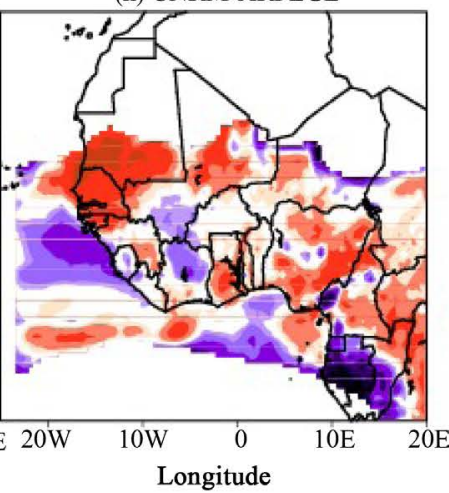

(l) Ens/RCMs

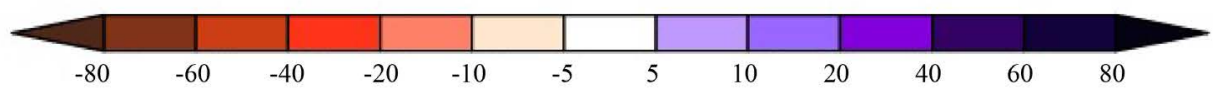

Figure 3. Relative bias (with respect to GPCP) for GPCP rainfall data (a), Era-interim reanalysis (b) regional climate models (c)-(k) and their ensemble mean (l) averaged during the summer time (June-September) from 1998 to 2008. The units are in mm/day for GPCP climatology and \% for the models and Era-Interim reanalysis biases. 

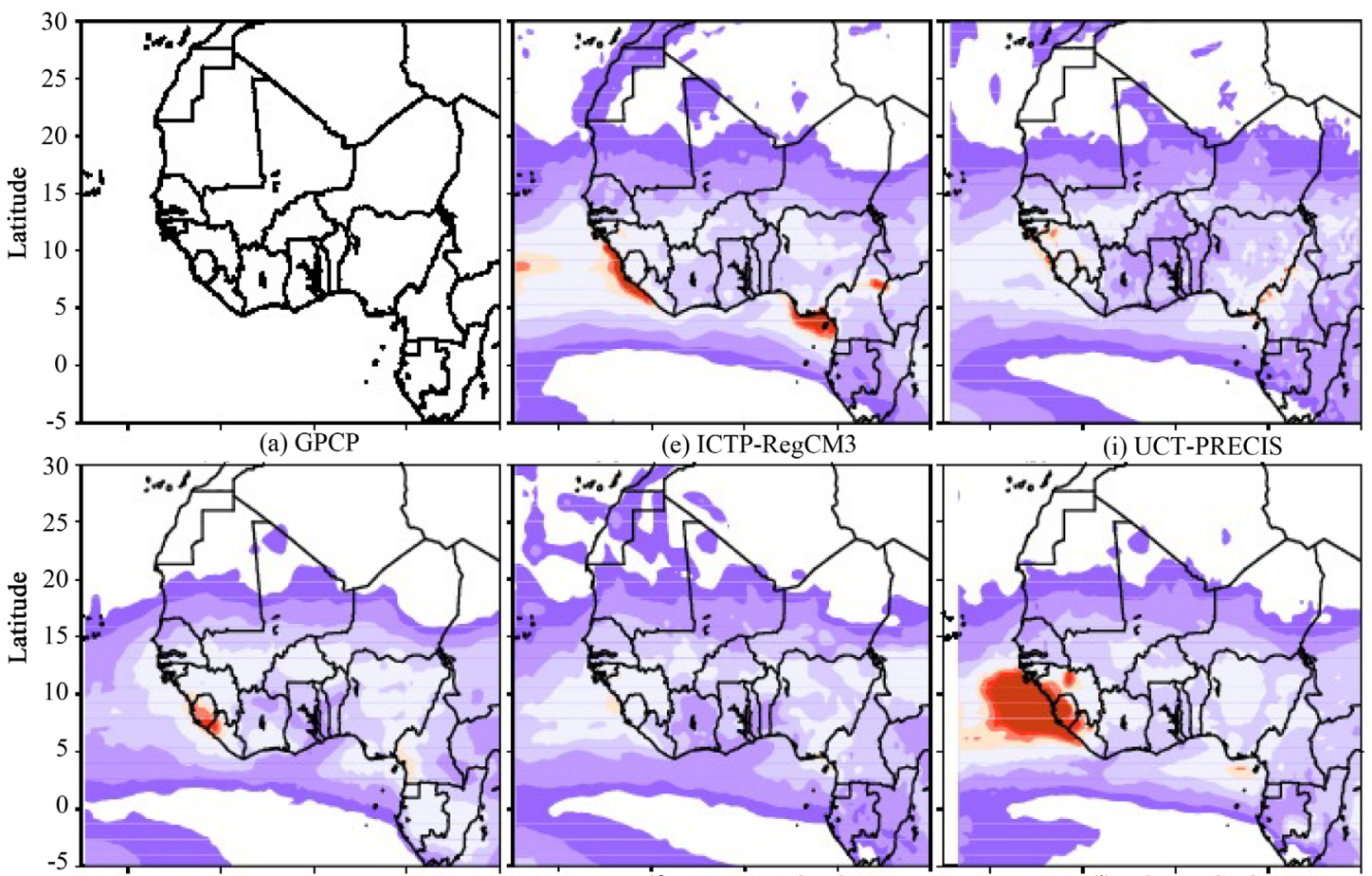

(e) ICTP-RegCM3

(i) UCT-PRECIS
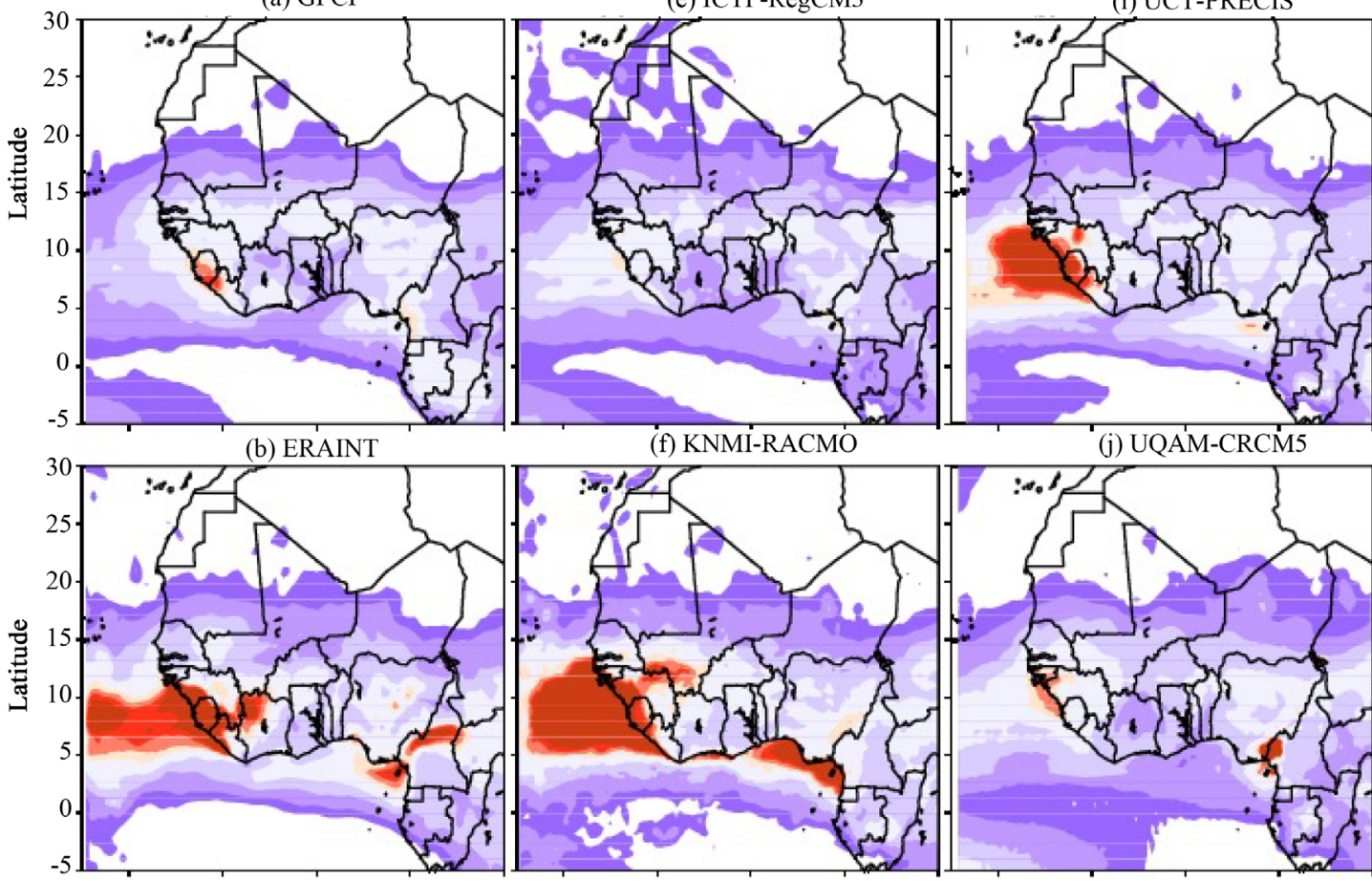

(f) KNMI-RACMO

(j) UQAM-CRCM5

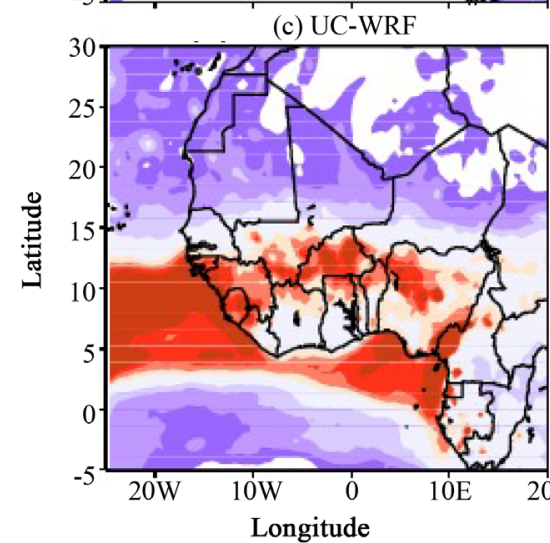

(d) DMI-HIRHAM

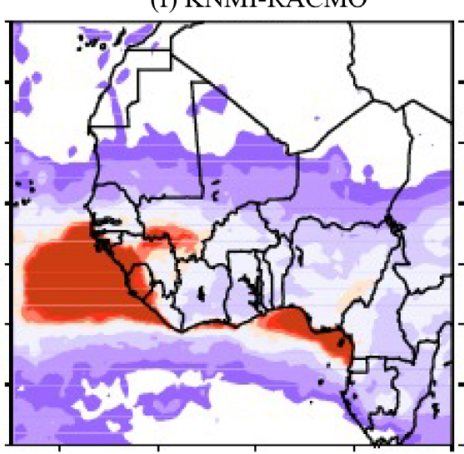

(g) MPI-REMO
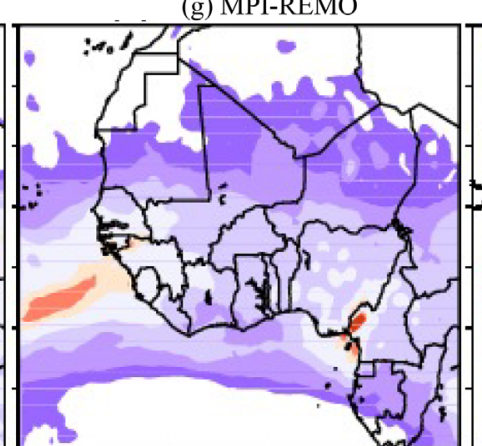

Longitude

(h) SMHI-RCA35
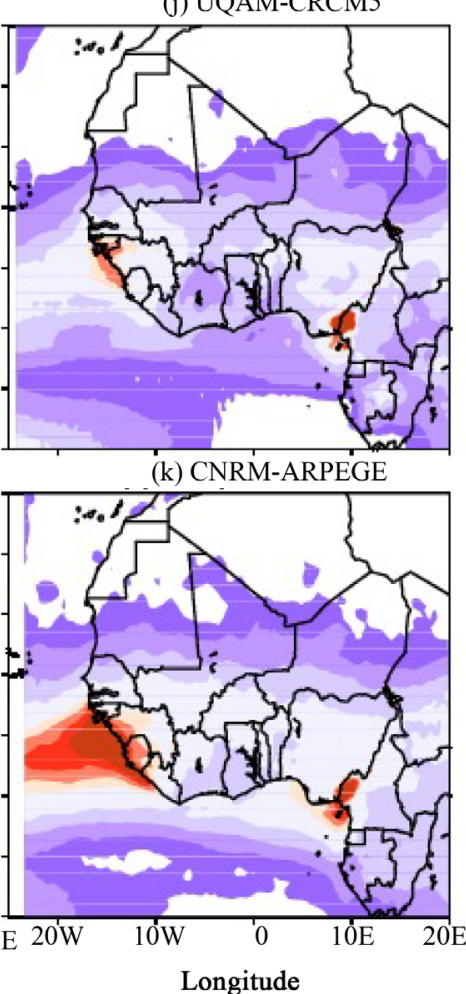

(k) CNRM-ARPEGE

(1) Bns/RCMs

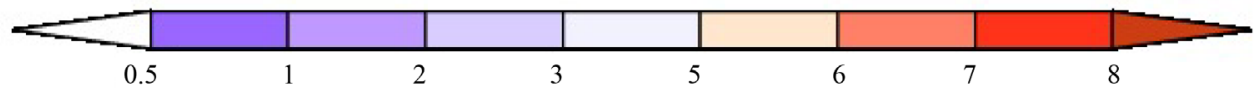

Figure 4. Root mean square error for the GPCP rainfall data (a), the forcing data Era-interim reanalysis (b) and the regional climate models (c)-(k) and their ensemble mean (l) averaged during the summer time from 1998 to 2008. 
Table 2. Mean summer relative anomaly of rainfall (from 1998 to 2008) with respect to GPCP climatology for CORDEX regional climate models, Era-Interim reanalyses over the Sahel (Western, central and Eastern) and the Guinea region. The unit is in \%.

\begin{tabular}{cccccccccccc}
\hline & CNRM & DMI & ERA & ICTP & KNMI & MPI & SMHI & UC & UCT & UQAM & Ens/RCMs \\
\hline $\begin{array}{c}\text { West } \\
\text { Sahel }\end{array}$ & -47.4 & -16.5 & -44.6 & -2.2 & -19.5 & 28.4 & -29.6 & -19.9 & -4.4 & -5.3 & -13 \\
$\begin{array}{c}\text { Central } \\
\text { Sahel }\end{array}$ & -40.7 & 5.5 & -60.8 & 21.1 & -2.6 & 8.8 & -17.1 & -8.6 & 26.1 & -37.1 & -5 \\
$\begin{array}{c}\text { Eastern } \\
\text { Sahel }\end{array}$ & -9.7 & -16.4 & -53.7 & 15.5 & -3.7 & -9.6 & -15.2 & -18.5 & 25.3 & -33.5 & $-7,3$ \\
\begin{tabular}{c} 
Guinea \\
\hline
\end{tabular} & -9.0 & 7.5 & 12.8 & -7.1 & -33.2 & 2.1 & 1.0 & 29.7 & -13.4 & 15.3 & -0.8 \\
\hline
\end{tabular}

Table 3. Mean summer root mean square errors of rainfall (from 1998 to 2008) with respect to GPCP climatology for CORDEX regional climate models and Era-Interim reanalyses over the Sahel (Western, central and Eastern) and the Guinea region. The unit is in $\mathrm{mm} /$ day.

\begin{tabular}{cccccccccccc}
\hline & CNRM & DMI & ERA & ICTP & KNMI & MPI & SMHI & UC & UCT & UQAM & Ens/RCMs \\
\hline $\begin{array}{c}\text { Western } \\
\text { Sahel }\end{array}$ & 3.2 & 4.6 & 2.9 & 2.6 & 2.9 & 4.1 & 3.0 & 2.9 & 2.7 & 2.8 & 2.7 \\
$\begin{array}{c}\text { Central } \\
\text { Sahel }\end{array}$ & 2.5 & 4.3 & 2.8 & 2.4 & 2.5 & 2.4 & 2.2 & 2.3 & 2.0 & 2.6 & 2.6 \\
$\begin{array}{c}\text { Eastern } \\
\text { Sahel }\end{array}$ & 2.0 & 3.1 & 2.2 & 1.9 & 2.1 & 1.6 & 1.9 & 1.8 & 1.7 & 2.1 & 2.6 \\
\begin{tabular}{c} 
Guinea \\
\hline
\end{tabular} & 2.7 & 6.0 & 2.8 & 2.8 & 2.3 & 3.4 & 2.8 & 3.7 & 2.5 & 2.9 & 3.2 \\
\hline
\end{tabular}

presents values of the order of $4.3 \mathrm{~mm} / \mathrm{d}$ over the central Sahel and $3.13 \mathrm{~mm} / \mathrm{d}$ over the Eastern Sahel. The Strongest value of RMSE is recorded over Guinean zone (around $6 \mathrm{~mm} / \mathrm{d}$ ) for DMI model.

When we considered the whole western Africa, strong values of RMSE are noted for DMI, MPI and WRF models. In summary, we note that although not presenting the strongest biases, the DMI model exhibits strong values of RMSE over the Sahel and the Guinean zone due to strong values of RMSE simulated south of $12^{\circ} \mathrm{N}$ (Figure 4).

The spatial distribution of the coefficient of correlation between the observation data and RCMs shows that all models (except HIRHAM) present positive values exceeding sometimes 0.6 over the Northern Sahel and the Gulf of Guinea (Figure 5). The ensemble mean shows the same pattern than the majority of RCMs but the northern positive correlation values are mainly located over and off the North-Western part of the Sahel (Senegal). However the model of DMI exhibits the weakest values of correlation. The Guinea region exhibits weak values of correlation coefficient. When considering the average over the sub-domains (Table 4), the CNRM model and the Era-Interim reanalyses present high values of correlation coefficient even if they present strong biases over the Western Sahel. RegCM3 and WRF models present a coefficient of correlation of the order of 0.6. Over the central Sahel, the RegCM3 model presents the strongest correlation. Over the Eastern Sahel, the strongest correlation coefficients are noted in the case of Era-Interim reanalyses and the WRF model. But over the Guinean zone, the values of the coefficient of correlation are generally weak and positive for engaged RCMs and the forcing data.

The standard deviation which is the measure of the interannual variability is computed in Figure 6 for the GPCP climatology, CORDEX RCMs and the Era-Intrim reanalyses. The GPCP climatology and the driving data (Era-Interim) show small values of standard deviation with values inferior to $3 \mathrm{~mm} /$ day. Most RCMs show weak values over the studied area except over and off the Guinea Highlands. REMO and HIRHAM contrary to other models exhibit values greater than $8 \mathrm{~mm} /$ day. The RCMs ensemble mean like most RCMs show weak values over the continent and slightly larger values (exceeding $5 \mathrm{~mm} /$ day) over and off the Guinea Highlands.

Table 5 shows the coefficient of variation for engaged models, Era-interim reanalysis and the GPCP climatology. The GPCP climatology presents values lower than 50\% over all sub-domains except over the Eastern 

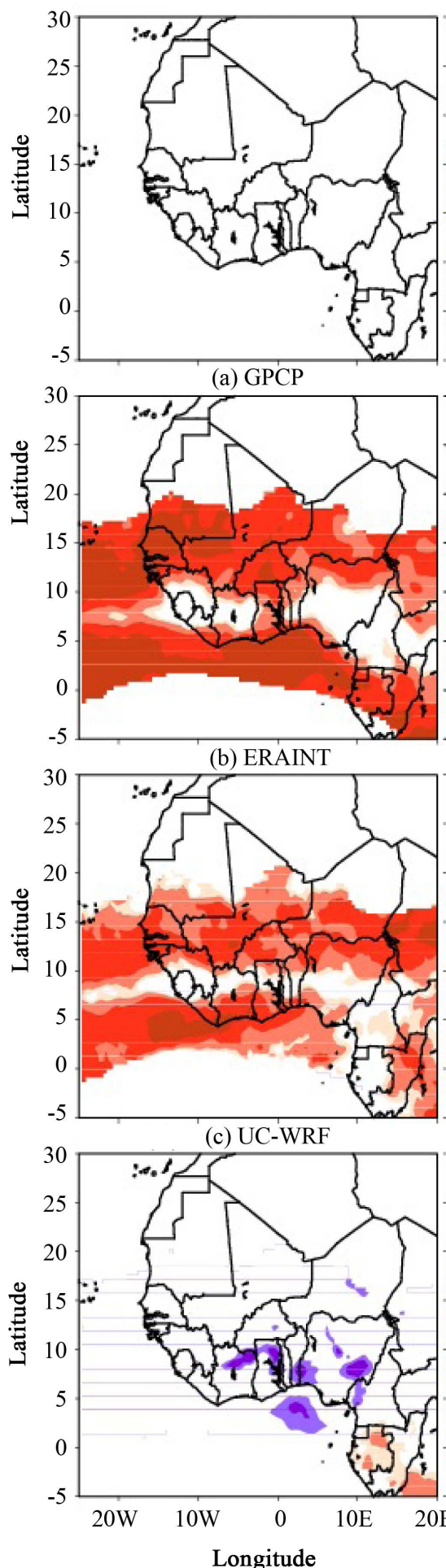

(d) DMI-HIPHAM

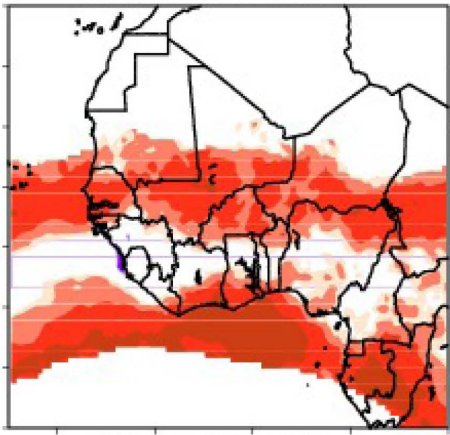

(e) ICTP-RegCM3

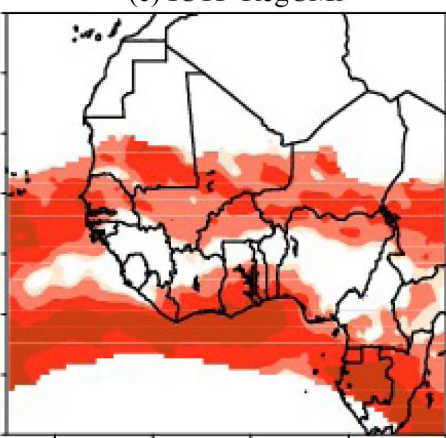

(f) KNMI-RACMO

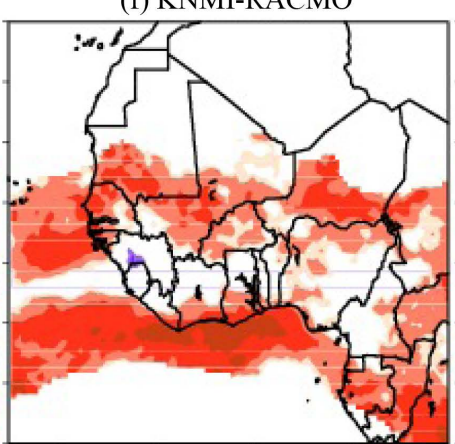

(g) MPI-REMO

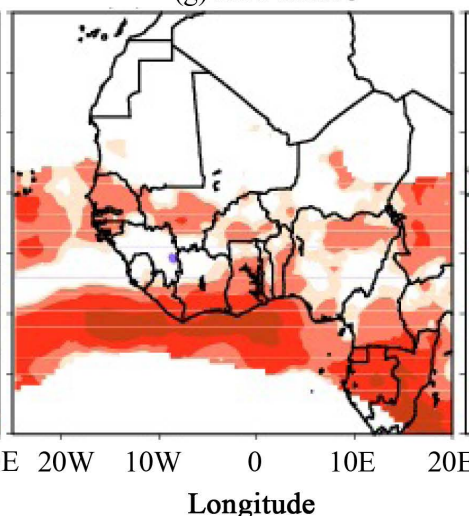

(h) SMHI-RCA35

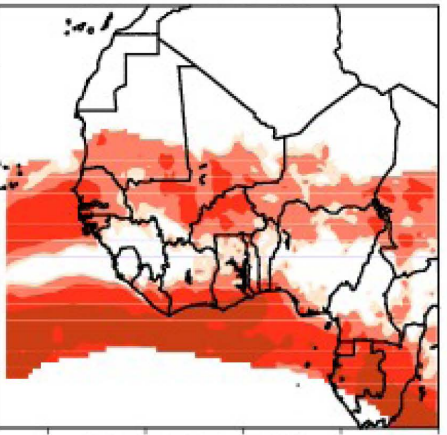

(i) UCT-PRECIS

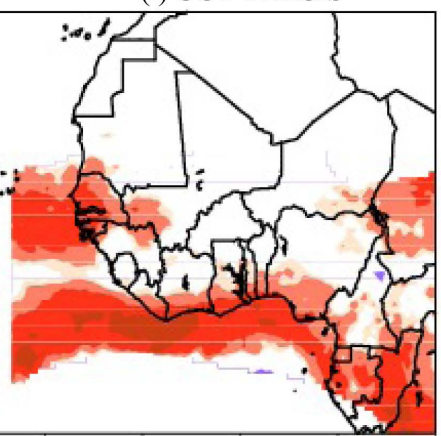

(j) UQAM-CRCM5

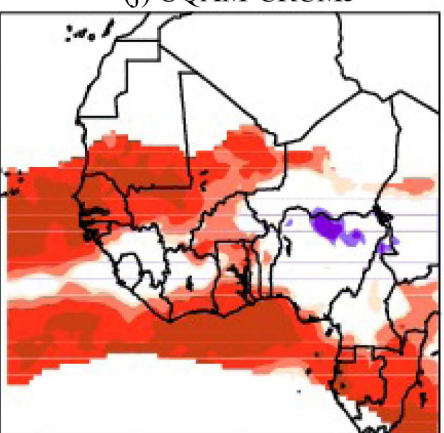

(k) CNRM-ARPEGE

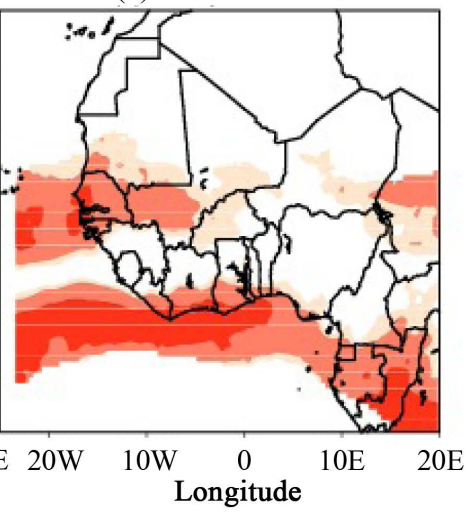

(l) Ens/RCMs

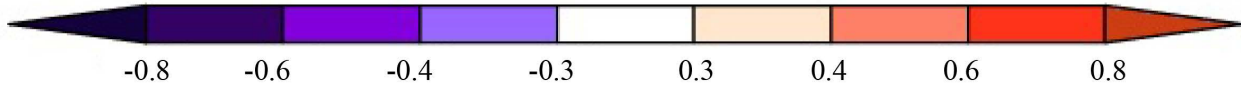

Figure 5. The Correlation coefficient between GPCP data and the forcing data Era-interim reanalysis (b), the regional climate models (c)-(k) and their ensemble mean (l) averaged during the summer time from 1998 to 2008. 

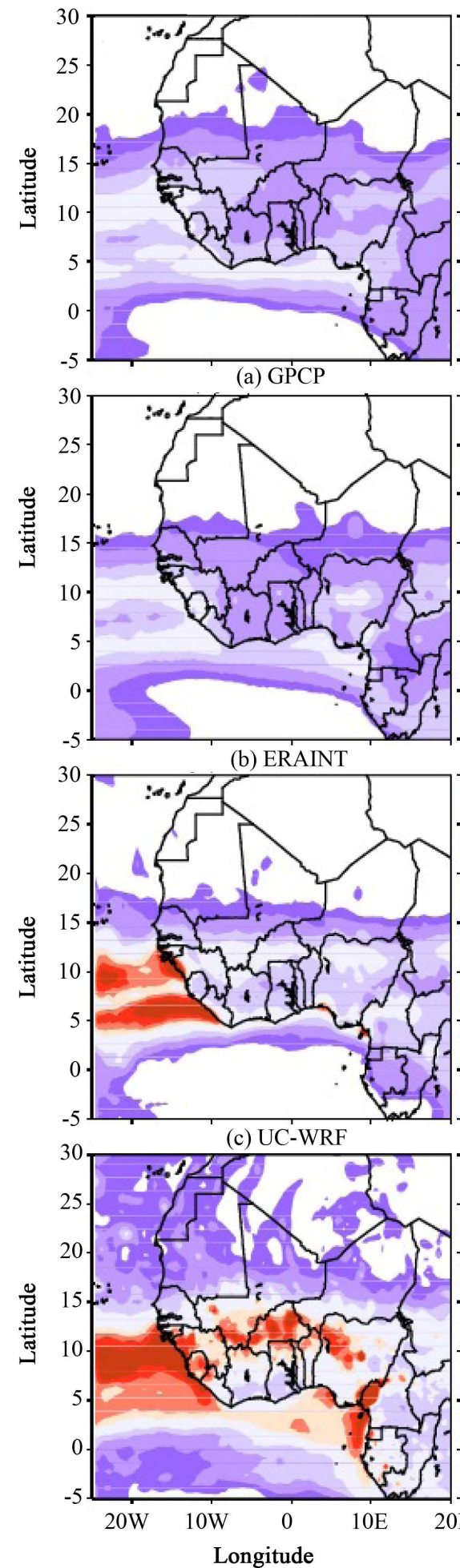

(d) DMI-HIRHAM

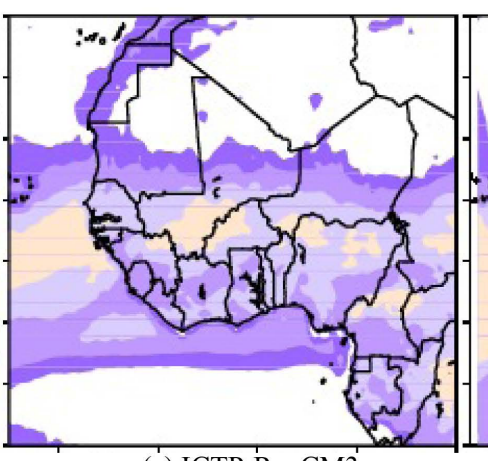

(e) ICTP-RegCM3

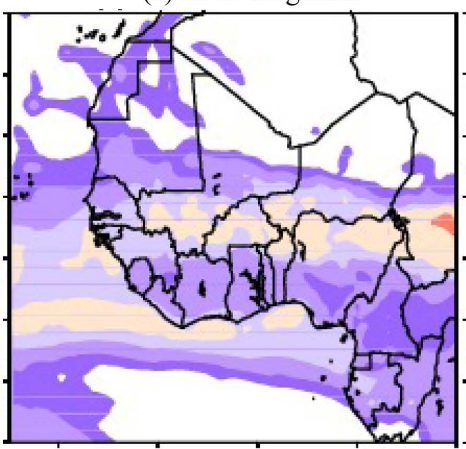

(f) KNMI-RACMO

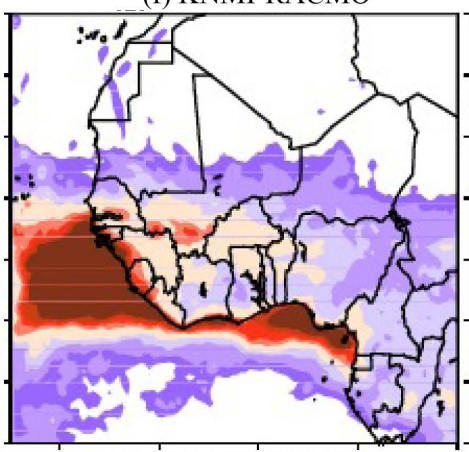

(g) MPI-REMO

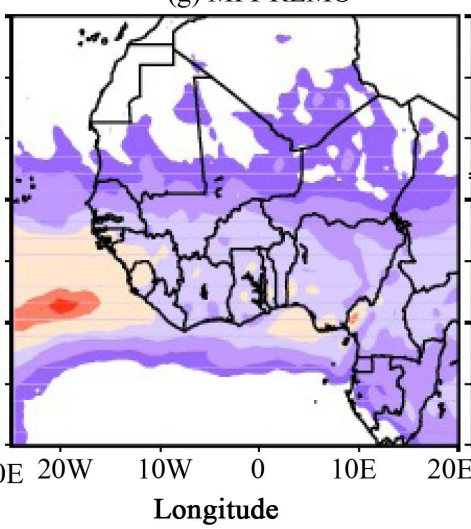

(h) SMHI-RCA35

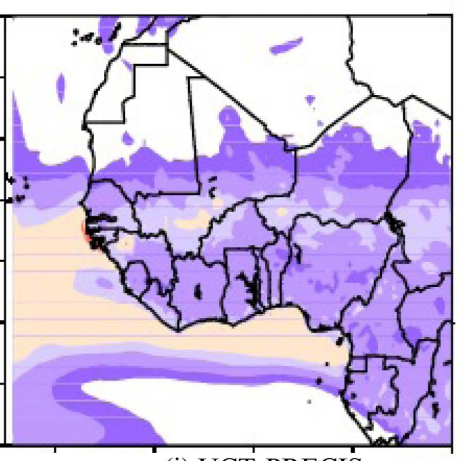

(i) UCT-PRECIS

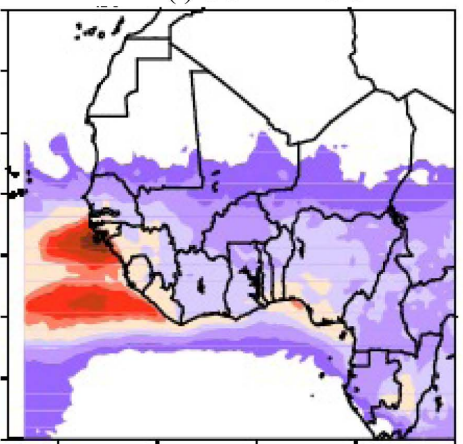

(j) UQAM-CRCM5

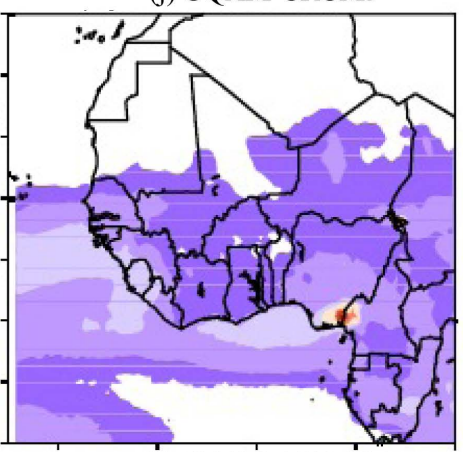

(k) CNRM-ARPEGE

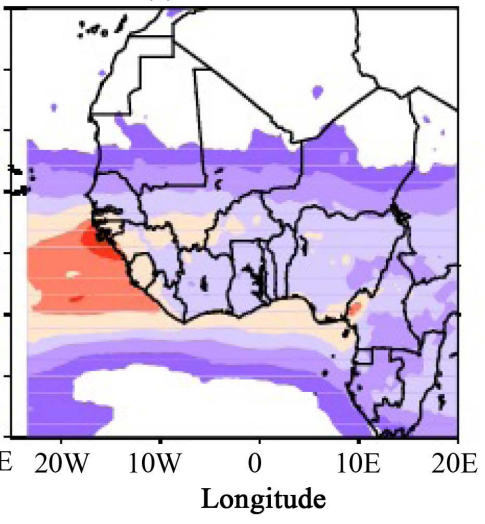

(l) $\mathrm{Bns} / \mathrm{RCMs}$

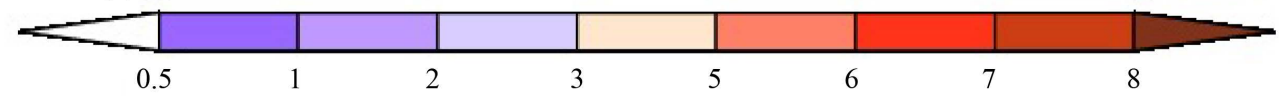

Figure 6. Standard deviation for the GPCP rainfall data (a), the forcing data Era-interim reanalysis (b) and the regional climate models (c)-(k) and their ensemble mean (l) averaged during the summer time from 1998 to 2008. 
Table 4. Coefficient of correlation between the observation data (GPCP) and CORDEX regional climate models and EraInterim reanalyses averaged over the Sahel (Western, Central and Eastern) and the Guinea region.

\begin{tabular}{ccccccccccccc}
\hline & CNRM & DMI & ERA & ICTP & KNMI & MPI & SMHI & UC & UCT & UQAM & Ens/RCMs \\
\hline $\begin{array}{c}\text { Western } \\
\text { Sahel }\end{array}$ & 0.7 & 0.0 & 0.7 & 0.5 & 0.5 & 0.4 & 0.3 & 0.6 & 0.5 & 0.2 & 0.4 \\
$\begin{array}{c}\text { Central } \\
\text { Sahel }\end{array}$ & 0.4 & -0.1 & 0.7 & 0.6 & 0.5 & 0.4 & 0.2 & 0.6 & 0.5 & -0.0 & 0.3 & \\
$\begin{array}{c}\text { Eastern } \\
\text { Sahel }\end{array}$ & 0.0 & -0.1 & 0.6 & 0.5 & 0.5 & 0.5 & 0.3 & 0.6 & 0.4 & 0.2 & 0.3 \\
Guinea & 0.3 & -0.2 & 0.3 & 0.4 & 0.4 & 0.3 & 0.4 & 0.4 & 0.4 & 0.4 & 0.3 \\
\hline
\end{tabular}

Table 5. Mean summer coefficient of variation (ratio between standard deviation and mean) of rainfall (from 1998 to 2008) for the GPCP climatology, CORDEX regional climate models and Era-Interim reanalyses over the Sahel (Western, Central and Eastern) and the Guinea region. The unit is in \%.

\begin{tabular}{ccccccccccccc}
\hline & GPCP & CNRM & DMI & ERA & ICTP & KNMI & MPI & SMHI & UC & UCT & UQAM & Ens/RCMs \\
\hline $\begin{array}{c}\text { Western } \\
\text { sahel }\end{array}$ & 48.7 & 49.4 & 101.6 & 64.4 & 58.9 & 88.9 & 62.3 & 57.2 & 69.9 & 44.9 & 49.1 & 64.7 \\
$\begin{array}{c}\text { Central } \\
\text { Sahel }\end{array}$ & 49.1 & 31.1 & 113.8 & 76.4 & 66.3 & 101.5 & 55.4 & 50.2 & 58.4 & 41.3 & 63.3 & 64.6 \\
$\begin{array}{c}\text { Eastern } \\
\text { sahel }\end{array}$ & 63.7 & 37.9 & 116.2 & 120.5 & 78.6 & 107.5 & 60.8 & 46.2 & 87.0 & 49.4 & 67.3 & 72.3 \\
$\quad \begin{array}{c}\text { Guinea } \\
\text { Guine }\end{array}$ & 35.3 & 21.6 & 68.3 & 29.1 & 44.1 & 50.0 & 55.9 & 42.8 & 42.2 & 30.8 & 42.4 & 44.2 \\
\hline
\end{tabular}

Sahel ( 63\%). The CNRM model presents a weak interannual fluctuation over most considered sub-domains; its interannual fluctuation is even weaker than the observed data (GPCP) over the three (3) other sub-domains (Central and Eastern Sahel and Guinea). The Precis model interannual fluctuations are weaker to the GPCP climatology over all sub-domains. However DMI and KNMI models present strong values of the coefficient of variation especially over the Sahelian band with average values that more important for the DMI model (Cv values reach $116 \%$ over the eastern Sahel). When we compared the Sahelian zone to the Guinean one, it appears that the interannual fluctuation of models is weaker over the Guinean region.

To summarize and better analyze the results obtained with sub-domains analysis, Taylor diagrams have been used to better evaluate the performance of RCMs by comparing normalized standard deviation (ration between the standard deviation and the mean) of GPCP data to the RCMs and the correlation coefficient between GPCP and the RCMs. Over the Western Sahel (Figure 7(a)), RACMO and HIRHAM models show a poor performance (strong standard deviation and weak correlation coefficient); while the ARPEGE model presents strong correlation and a standard deviation slightly stronger than the observation data.

Over the Central Sahel (Figure 7(b)), CORDEX RCMs generally present a weak performance. The forcing data (Era-interim) shows the greatest correlation coefficient with a standard deviation larger than the observation (0.75). The same trend is present over the Eastern Sahel (Figure 7(c)). The correlation coefficient is generally weak but the ARPEGE model shows a standard deviation weaker than the observation data. Over the Guinea region (Figure $7(d)$ ), the RCMs present weak correlation coefficient $(<0.4)$ and standard deviation values.

\section{Conclusions}

This work aims to estimate the systematic errors of regional climate models engaged in CORDEX project by analyzing the spatial distribution of some statistical parameters such as the root mean square errors (RMSE), the relative bias, the standard deviation and the coefficient of correlation over West Africa.

The first step was to analyze the spread between observed data generally used over West Africa for model validation purposes. Most of them are a combination of in situ measurements (rain gauges) and satellite products. The analysis of the relative bias with respect to GPCP climatology highlights the big uncertainty on the quality of these observed rainfall data over West Africa; this is largely due to the rarity of in situ measurements especially over some areas like mountainous, forest and desert regions. The mean ensemble shows weaker biases 


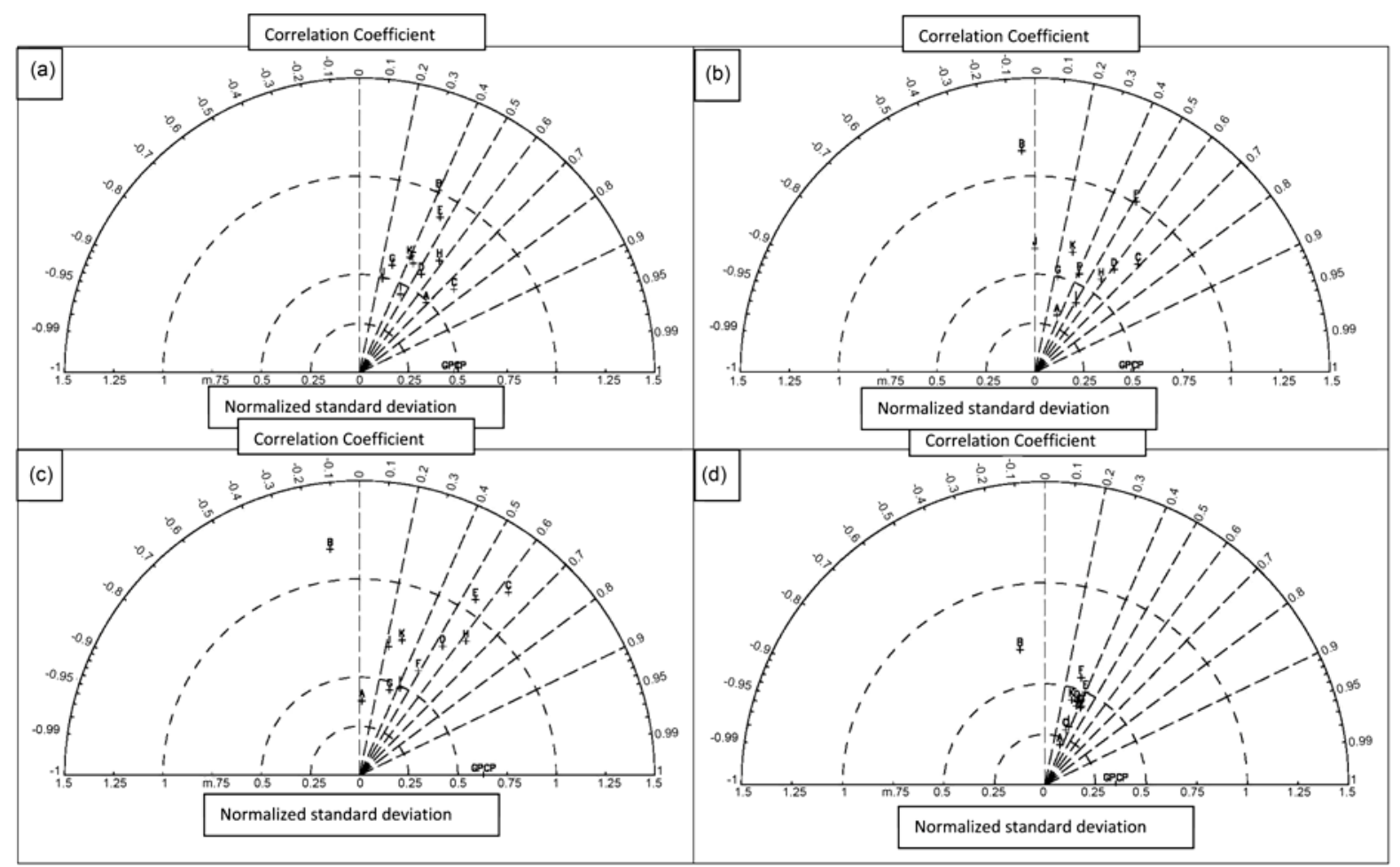

Figure 7. Taylor diagram over the (a) Western Sahel, (b) Central Sahel, (c) Eastern Sahel and (d) Guinea region. The observation data is the GPCP climatology. RCMs are A: CNRM-ARPEGE, B: DMI-HIRHAM, D: ICTP-RegCM3, E: KNMIRACMO, F: MPI-REMO, G: SMHI-RCA, H: UC-WRF, I: UCT-PRECIS, J: UQAM-CRCM5 and K: Ens/RCMs. C is for ERA-INTERIM.

than individual RCMs suggesting that this ensemble approach may be a solution to consider when validating RCMs rainfall outputs over West Africa.

The analysis of the relative bias of regional climate models and their ensemble mean with respect to GPCP shows that the ensemble mean presents the weakest relative change. The forcing data (Era-Interim) present an opposite structure when compared to some models (Precis model); this result highlights the fact that the solution simulated by regional climate models does not depend only on the forcing and initialization data but the internal variability of the latters may play a greater role. The root mean square error (RMSE) is weak over West Africa except over and off the Guinea highlands for considered RCMs. This region (Guinea Highlands) is characterized by a lack of in situ measurements (rain gauges data) suggesting that the RCMs due to their fine spatial resolution may even be better than observation which are essentially satellite estimates over and off this mountainous region. This fine spatial resolution allows RCMs to resolve local features, such as the orography, that are known to be important for the physical response of the climate [11]. The DMI model shows the greatest RMSE especially over the ocean; while the RegCM3 and PRECIS models present the weakest values over the studied region. The ensemble means like most of RCMs exhibit strong values off Fouta Djallon highlands.

The spatial distribution of the coefficient of correlation between the observation data and RCMs show that all models (except HIRHAM) present positive values over the Northern Sahel and the Gulf of Guinea. The southern Sahel-Guinea region seems to be poorly correlated with GPCP observation.

The analysis of biases over 4 sub-domains (Western Sahel, Central Sahel, Eastern Sahel and Guinea) with regard to the GPCP data showed that over the Sahel, the RCMs except the CNRM model and the forcing data (Era-interim) present low biases. When considering the Guinean zone, the biases are generally low for all the considered datasets. The RMSE analysis shows that the DMI model presents strong values as well in Guinean zone than over Sahel despite the fact that its biases are relatively low. The MPI model experiences the same difficulties (strong values of RMSE) over the Western Sahel and the Guinean zone. The correlation coefficient is generally low over the Guinean zone. Over the Sahel, the strongest values (close to 70\%) are noted in the case of the forcing data. The WRF model presents values reaching 0.7 over the eastern and western Sahel; while the 
CNRM model presents a strong correlation with the GPCP data over the western Africa.

Finally, this box average analysis highlights the good performance of the WRF model over the Sahel because it presents a weak bias and a weak RMSE coupled with strong values of correlation coefficient.

In conclusion, the RCMs show a good ability to simulate the present climate over West Africa. However it is necessary to note the presence of uncertainties on the future climate because of systematic biases which exist in the RCMs simulation and one must take that into account when performing climate change impacts studies with CORDEX RCMs products.

\section{Acknowledgements}

The authors would like to acknowledge the International Center for Theoretical Physics (ICTP) associateship program and the Assane SECK University of Ziguinchor (Senegal) for their support.

\section{References}

[1] James, R., Washington, R. and Rowell, D.P. (2014) African Climate Change Uncertainty in Perturbed Physics Ensembles: Implications of Global Warming to $4^{\circ} \mathrm{C}$ and Beyond. Journal of Climate, 27, 4677-4692. http://journals.ametsoc.org/doi/abs/10.1175/JCLI-D-13-00612.1

[2] Skinner, C.B. and Diffenbaugh, N.S. (2014) Projected Changes in African Easterly Wave Intensity and Track in Response to Greenhouse Forcing. Proceedings of the National Academy of Sciences of the United States of America, 111, 6882-6887. http://www.pnas.org/content/early/2014/04/23/1319597111.abstract

[3] Taylor, K.E., Stouffer, R.J. and Meehl, G.A. (2012) An Overview of CMIP5 and the Experiment Design. Bulletin of American Meteorology Society, 93, 485-498. http://dx.doi.org/10.1175/BAMS-D-11-00094.1

[4] Rummukainen, M. (2010) State-of-the-Art with Regional Climate Models. Climate Change, 1, $96-82$. http://dx.doi.org/10.1002/wcc.8

[5] Giorgi, F and Mearns, L.O. (1999) Introduction to Special Section: Regional Climate Modeling Revisited. Journal of Geophysical Research, 104, 6335-6352. http://dx.doi.org/10.1029/98JD02072

[6] Paeth, H., Capo-Chichi, A. and Endlicher, W. (2008) Climate Change and Food Security in Tropical West Africa-A Dynamic-Statistical Modelling Approach. Erdkunde, 62, 101-115. http://dx.doi.org/10.3112/erdkunde.2008.02.01

[7] Philippon, N., Martiny, N. and Camberlin, P. (2009) Forecasting the Vegetation Photosynthetic Activity over the Sahel: A Model Output Statistics Approach. International Journal of Climatology, 29, 1463-1477. http://dx.doi.org/10.1002/joc.1797

[8] Hoerling, M, Hurrell, J., Eischeid, J. and Phillips, A. (2006) Detection and Attribution of Twentieth-Century Northern and Southern African Rainfall Change. Journal of Climate, 19, 3989-4008. http://dx.doi.org/10.1175/JCLI3842.1

[9] Afiesimama, A.E., Pal, J.S., Abiodun, B.J., Gutowski, W.J. and Adedoyin, A. (2006) Simulation of West African Monsoon Using the RegCM3. Part I: Model Validation and Interannual Variability. Theoretical and Applied Climatology, 86, 23-37. http://dx.doi.org/10.1007/s00704-005-0202-8

[10] Hsieh, J.S, and Cook, K.H. (2007) A Study of the Energetic of African Easterly Waves Using Regional Climate Model. Journal of the Atmospheric Sciences, 64, 421-440. http://dx.doi.org/10.1175/JAS3851.1

[11] Sylla, M.B., Dell’Aquila, A., Ruti, P.M. and Giorgi, F. (2010) Simulation of the Intraseasonal and the Interannual Variability of Rainfall over West Africa with RegCM3 during the Monsoon Period. International Journal of Climatology, 30, 1865-1883.

[12] Van der Linden, P. and Mitchell, J.F.B. (2009) ENSEMBLES: Climate Change and Its Impact: Summary of Research and the Results from the ENSEMBLES Project. Met Office Hadley Centre, Exeter.

[13] Nikulin, G., Jones, C., Giorgi, F., Asrar, G., Buchner, M., Cerezo-Mota, R., et al. (2012) Precipitation Climatology in an Ensemble of CORDEX-Africa Regional Climate Simulations. Journal of Climate, 25, 6057-6078. http://dx.doi.org/10.1175/JCLI-D-11-00375.1

[14] Camara, M., Diedhiou, A., Sow, B.A., et al. (2013) Analyse de la pluie simulée par les modèles climatiques régionaux de CORDEX en Afrique de l'Ouest. Sécheresse, 24, 14-28.

[15] Gbobaniyi, E., Sarr, A., Sylla, M.B., et al. (2013) Climatology, Annual Cycle and Interannual Variability of Precipitation and Temperature in CORDEX Simulations over West Africa. International Journal of Climatology, 34, 2241-2257. http://dx.doi.org/10.1002/joc.3834

[16] Kim, J., Waliser, D.E., Mattmann, C.A., Goodale, C.E., Hart, A.F., Zimdars, P.A., et al. (2014) Evaluation of the CORDEX-Africa Multi-RCM Hindcast: Systematic Model Errors. Climate Dynamics, 42, 1189-1202.

http://dx.doi.org/10.1007/s00382-013-1751-7 
[17] Déqué, M. (2010) Regional Climate Simulation with a Mosaic of RCMs. Meteorologische Zeitschrift, 19, $259-266$. http://dx.doi.org/10.1127/0941-2948/2010/0455

[18] Christensen, O.B., Drews, M., Christensen, J.H., Dethloff, K., Ketelsen, K., Hebestadt, I. and Rinke, A. (2008) The Hirham Regional Climate Model Version 5. Technical Report 06-17, DMI. http://www.dmi.dk/dmi/en/print/tr06-17.pdf

[19] Pal, J.S., Giorgi, F., Bi, X., Elguindi, N., Solmon, F., Gao, X., Rauscher, S.A., Francisco, R., Zakey, A., Winter, J., Ashfaq, M., Syed, F.S., Bell, J.L., Diffenbaugh, N.S., Karmacharya, J., Konare, A., Martinez, D., da Rocha, R.P., Sloan, L.C. and Steiner, A.L. (2007) Regional Climatemodeling for the Developing World-The ICTP RegCM3 and RegCNET. Bulletin of the American Meteorological Society, 88, 1395-1409. http://dx.doi.org/10.1175/BAMS-88-9-1395

[20] Jacob, D., Barring, L., Christensen, O.B., Christensen, J.H., Hagemann, S., Hirschi, M., Kjellström, E., Lenderink, G., Rockel, B., Schar, C., Seneviratne, S.I., Somot, S., van Ulden, A. and van den Hurk, B. (2007) An Inter-Comparison of Regional Climate Models for Europe: Design of the Experiments and Model Performance. Climate Change, 81, 31-52. http://dx.doi.org/10.1007/s10584-006-9213-4

[21] Meijgaard, E., van Ulft, L.H., van den Berg, W.J., Bosveld, F., van den Hurk, B., Lenderink, G. and Siebesma, A.P. (2008) The KNMI Regional Atmospheric Climate Model RACMO, Version 2.1. KNMI Technical Report 302, 43.

[22] Jones, R., Noguer, M., Hassel, D., Hudson, D., Wilson, S., Jenkins, G. and Mitchell, J. (2004) Generating High Resolution Regional Climate Change Using PRECIS. Met Office Hadley Centre, Exeter, 40.

[23] Samuelsson, P., Jones, C.G., Willén, U., Ullerstig, A., Gollvik, S., Hansson, U., Jansson, C., Kjellström, E., Nikulin, G. and Wyser, K. (2011) The Rossby Centre Regional Climate Model RCA3: Model Description and Performance. Tellus A, 63, 4-23. http://dx.doi.org/10.1111/j.1600-0870.2010.00478.x

[24] Skamarock, W.C., Klemp, J.B., Dudhia, J., Gill, D.O., Barker, D.M., Wang, W. and Powers, J.G. (2008) A Description of the Advanced Research WRF Version 3. NCAR Tech 15 Note NCAR/TN-475+STR, 113.

[25] Zadra, A., Caya, D., Côté, J., Dugas, B., Jones, C., Laprise, R., Winger, K. and Caron, L. (2008) The Next Canadian Regional Climate Model. Physics in Canada, 64, 75-83.

[26] Uppala, S.M., Dee, D., Kobayashi, S., et al. (2008) Towards a Climate Data Assimilation System: Status Update of ERA-Interim. ECMWF Newsletter, 115, 12-18.

[27] Adler, R.F., Huffman, G.J., Charney, J.G., Chang, A., et al. (2003) The Version-2 Global Precipitation Climatology Project (GPCP) Monthly Precipitation Analysis (1979-Present). Journal of Hydrometeorology, 4, 1147-1167. http://dx.doi.org/10.1175/1525-7541(2003)004<1147:TVGPCP >2.0.CO;2

[28] Huffman, G.J., Adler, R.F., Bolvin, D.T., et al. (2007) The TRMM Multisatellite Precipitation Analysis (TMPA): Quasi-Global, Multiyear, Combined-Sensor Precipitation Estimates at Fine Scales. Journal of Hydrometeorology, 8, 38-55. http://dx.doi.org/10.1175/JHM560.1

[29] Rudolf, B., Becker, A., Schneider, U., Meyer-Christoffer, A. and Ziese, M. (2010) The New "GPCC Full Data Reanalysis Version 5” Providing High-Quality Gridded Monthly Precipitation Data for the Global Land-Surface Is Public Available since December 2010. GPCC Status Report, December 2010, 7 p.

[30] Mitchell, T.D. and Jones, P.D. (2005) An Improved Method of Constructing a Database of Monthly Climate Observations and Associated High-Resolution Grids. International Journal of Climatology, 25, 693-712. http://dx.doi.org/10.1002/joc.1181

[31] Legates, D.R. and Willmott, C.J. (1990) Mean Seasonal and Spatial Variability in Gauge-Corrected, Global Precipitation. International Journal of Climatology, 10, 111-127. http://dx.doi.org/10.1002/joc.3370100202

[32] Jobard, I., Chopin, F., Berges, J.C. and Roca, R. (2011) An Intercomparison of 10-Day Satellite Precipitation Products during West African Monsoon. International Journal of Remote Sensing, 32, 2353-2376. http://dx.doi.org/10.1080/01431161003698286 